University of Rhode Island

DigitalCommons@URI

Open Access Dissertations

1985

\title{
The Role of the Orientation Response in the Cognitive Control of Leveling and Sharpening
}

David J. Libon

University of Rhode Island

Follow this and additional works at: https://digitalcommons.uri.edu/oa_diss

\section{Recommended Citation}

Libon, David J., "The Role of the Orientation Response in the Cognitive Control of Leveling and Sharpening" (1985). Open Access Dissertations. Paper 920.

https://digitalcommons.uri.edu/oa_diss/920

This Dissertation is brought to you for free and open access by DigitalCommons@URI. It has been accepted for inclusion in Open Access Dissertations by an authorized administrator of DigitalCommons@URI. For more information, please contact digitalcommons-group@uri.edu. 
THE ROLE OF THE ORIENTATION RESPONSE

IN THE COGNITIVE CONTROL OF

LEVELING AND SHARPENING

BY

DAVID J. LIBON

A DISSERTATION SUBMITTED IN PARTIAL FULFILLMENT OF THE REQUIREMENT FOR THE DEGREE OF

DOCTOR OF PHILOSOPHY IN

PSYCH OLOGY 
Heart rate orientation responses were taken while subjects were administered two tests of leveling and sharpening. The first leveling and sharpening test was neutral in content while the second was designed to be affectively arousing. Subjects were also administered the aggression scale from the Edwards Personal Preference Scale (EPPS) and classified into low and high aggression groups. It was predicted that the use of attention is a major cognitive distinction between levelers and sharpeners. Heart rate orientation responses were used as a measure of attention. It was predicted that sharpeners would exhibit greater orienting behavior than levelers and these attentional differences would be further elucidated by changes in the content of the two leveling and sharpening tasks and by subjects' predisposition towards the trait of aggression. Repeated measures ANOVA showed a significant main effect for task with a decrease in orienting behavior as subjects went from the neutral leveling-sharpening task to the affectively arousing leveling-sharpening task and a significant 3-way interaction with high EPPS-aggression sharpeners and low EPPS-aggression levelers exhibiting significantly different patterns of orientation responses between the levelingsharpening tasks. 
Acknow ledgement

I wish to express my gratitude to many persons who made this dream come true: Dr. Dominic Valentino, Dr. Jack Demick, Dr. Charles Collyer, and Dr. Stan Weber; special thanks go to Dr. Valentino for his support and encouragement; to Dr. Nelson Smith for supplying laboratory space; to my friends and colleagues who believed in me and were always there for encouragement and advice. 
Dedication

To the Doc behind the Doc. 
Contents

Abstract i i

Acknowledgement ii

Dedication iil

Table of Contents iv

List of Tables v v

List of Figures vi

Introduction 1

Cognitive Controls: A Historical Perspective 6

The Cognitive Control of Leveling and sharpening 10

Leveling and Sharpening Under Affective Conditions 15

The Orientation Response 21

The OR: Psychological Correlates 25

Hypotheses and Predictions 32

Method $\quad 34$

$\begin{array}{ll}\text { Subjects } & 34\end{array}$

Instruments $\quad 34$

$\begin{array}{ll}\text { Procedure } & 35\end{array}$

$\begin{array}{ll}\text { Data Analysis } & 37\end{array}$

$\begin{array}{ll}\text { Results } & 40\end{array}$

Discussion $\quad 50$

$\begin{array}{ll}\text { References } & 64\end{array}$

$\begin{array}{ll}\text { Appendix A } & 67\end{array}$

$\begin{array}{ll}\text { Appendix B } & 70\end{array}$ 
List of Tables

Table 1. Score sheet for LSHT

Table 2. Score sheet for LSAT

Table 3. Means, Ranges and Standard Deviations for All

Variables

Table 4. Means, Ranges and Standard Deviations for

Sharpeners

Table 5. Means, Ranges and Standard Deviations for Levelers

Table 6. ANOVA Source Table, Leveling-Sharpening $x$ EPPS-Aggression $\mathrm{x}$ Tasks

Table 7. Means and Standard Deviations for Heart Rate Charge Scores for High and Low Aggression Subjects on the Leveling-Sharpening House Test and Level ing-Sharpening Aggression Test 
List of Figures

Figure 1. The Leveling-Sharpening House Test

Figure 2. The Leveling-Sharpening Aggression Test

Figure 3. Trial segments

Figure 4. Heart Rate Change Scores for High and Low Aggression Subjects on the Leveling-Sharpening House Test and Leveling-Sharpening Aggression Test 
Introduction

The purpose of this research is to investigate the relationship between the cognitive control of leveling and sharpening and the orientation response $(O R)$, a psychophysiological measure of attention. There have been very few extensive or systematic studies of how the various dimensions within any single cognitive control may differ psychophysiologically. The cognitive control of interest in this research is the cognitive control of leveling and sharpening. Israel (1966) defines leveling and sharpening as follows: sharpeners are those persons who are characterized by an attentive orientation towards the details of external stimuli and by a tendency to focus on the differences rather than the similarities between stimuli. Thus, upon successive presentations of stimuli the discreteness of novel stimuli is maintained. Levelers are those persons who are characterized by inattention towards the details of external stimuli and a tendency to focus on the similarities rather than the differences between stimuli. Upon successive presentations of stimuli the fine distinctions between stimuli are not maintained. Thus, novel stimuli lose their discreteness.

The field of cognitive controls has had a long history (Klein 1954; Gardner et al., 1959). Its origins are related to psychoanalytic ego psychology and the New Look theory of perception. From their beginning, cognitive controls have 
been considered to be intervening variables whose function is to mediate between environmental stimulation and the individual's response to that stimulation. Thus, from a cognitive point of view the concept of cognitive controls has always been polyglot. An examination of the face validity of any single cognitive control indicates that it may be composed of a variety of separate cognitive processes. For example, leveling and sharpening have been described as involving both memory and attentional processes. This research will focus upon and seek to quantify psychophysiologically the attentional component of this phenomenon.

The attentional component of leveling and sharpening will be guantified psychophysiologically by examining the orientation responses (OR) of subjects while they are actually performing leveling and sharpening tasks. Since past research employing psychological tests has suggested that there are cognitive differences between leveling and sharpening behavior, it is not unreasonable to expect that this differentiation would be reflected psychophysiologically. The psychophysiological response system that will be employed in the assessment of the OR in this research is heart rate (HR). Lacey and Lacey (1980) have shown that the heart rate component of the $O R$ is a reliable index of psychophysiological aspects of attention. The only previous psychophysiological research that has been conducted with levelers and sharpeners is a series of 
studies carried out by Israel (1966, 1969.) Using a different methodological approach, this research will attempt to extend her findings.

The specific aims of the present research are as follows. Firstly, it is desired to see if psychophysiological measures of heart rate can differentiate between levelers and sharpeners while subjects are engaged in leveling-sharpening tasks. No researcher, including Israel, has ever examined the psychophysiology of leveling and sharpening while subjects were actually performing levelingsharpening tasks. It is hypothesized that levelers and sharpeners differ with respect to attention and that it is this attentional difference that determines the direction of the leveling-sharpening principle. It is predicted, therefore, that this attentional difference will be manifested by differing patterns of heart rate orientation responses while subjects are performing their respective leveling and sharpening tasks.

The second aim of this research is to see how the attentional behavior of levelers and sharpeners and their concommitant psychophysiological responses are altered when the signal value of the leveling-sharpening task changes from neutral to affectively arousing. It is hypothesized that if attention truly accounts for a significant difference between levelers and sharpeners then this difference should be further elucidated when attention is measured across leveling and sharpening tasks of differing 
signal value. It is predicted that when the signal value of leveling-sharpening tasks changes from neutral to affectively arousing, there will be concomitant changes in orienting behavior that will further differentiate levelers and sharpeners.

Thus the leveling-sharpening tasks that will be used in this research will be of two types. The first task makes use of a leveling-sharpening instrument that is neutral in content. This task is the Leveling-Sharpening House Test (LSHT). The second task is designed to be affectively arousing. This task is the Leveling-Sharpening Aggression Test (LSAT). Both of these tests have been developed by Santostefano (1978, 1983). The construction, administration and scoring of these tasks are identical. The only difference is the content of the stimulation.

In addition to cognitive control (i.e., levelerssharpeners) and type of task (i.e. neutral/affective) a third independent variable will be manipulated in this research. This will be an outside criterion measure of aggression separate from the LSAT. The Edwards Personal Preference Schedule (EPPS, 1959) will be used to further separate subjects into high and low aggression groups.

There are three aspects to this research. First, differences between levelers and sharpeners in attention as measured by heart rate orienting behavior will be examined. Second, psychophysiological differences in attention will be measured as the signal value of leveling and sharpening 
tasks changes from a task that is neutral in content (LSHT) to a task that is affectively arousing (LSAT). Finally, subjects will be divided into high and low aggression groups on the basis of the Edwards Personal Preference Schedule (EPPS) to see how a subject's predisposition towards aggression influences the cognitive control of leveling and sharpening.

These procedures represent substantial methodological improvements over past psychophysiological research that has been conducted with the leveling-sharpening phenomenon. It is expected that with these improvements a more precise and accurate psychophysiological differentiation between levelers and sharpeners can be made. 
Cognitive Controls: A Historical Perspective

In general terms, cognitive controls are viewed as unique, relatively permanent mechanisms employed by the individual to organize information that becomes available from the environment (Garaner et al., 1959). Much research using cognitive controls has been conducted since the concept was introduced more than 35 years ago (KIein and Schlesinger, 1949). The original intent of cognitive control research was to define and elucidate the parameters of what Hartmann (1959) called the "conflict-free ego". The conflict-free ego is defined as that portion of the ego that regulates such cognitive activities as memory, perception, and attention. Thus, cognitive controls may be thought of as taking on the status of intervening variables employed by the ego in the regulation between environmental stimulation and the individual's response to that stimulation.

One of the first attempts to systematize the field of cognitive control research was made in 1959 by Riley Gardner, Philip Holzman, and their colleagues. Their objective was straightforward: "To discover the most general regulatory principles that determine a person's responses and account for individual differences among people" (p. 6). In their research, Gardner and Holzman were concerned with six separate and, in their minds, totally unique cognitive control principles. Each cognitive control principle was unique because of the type of cognitive behavior it 
attempted to describe. An important element that Gardner and his co-workers bring to this field of study is their assumption of the hierarchical organization of their six cognitive controls. This means that the development of cognitive controls follows a specific ontological sequence and that the individual must master the elements of the initial cognitive controls before mastery is attained with those cognitive controls that develop later. Thus, the principles of early cognitive controls are subsumed and are incorporated into those cognitive controls that follow.

Another distinguishing feature of the Gardner group's approach to cognitive controls is their emphasis upon the adaptive significance cognitive controls exercise in cognitive functioning and personality. The ultimate purpose of the Gardner group's work was to illustrate the significance of cognitive controls as they relate to personality. At least implicitly, Gardner and Holzman desired to show that cognitive controls are involved in an informational feedback system and that this is related to how individuals react to affectively arousing stimuli.

A second major effort to systematize the field of cognitive controls was made in 1978 by Sebestiano Santostefano. Santostefano is a child clinical psychologist whose theoretical orientation is very similar to the Gardner group's. While also trained in psychoanalysis, Santostefano's approach to the field of cognitive controls is essentially developmental in nature. Drawing from the 
work of Werner and Piaget as well as from the ego psychology of the 1950's, Santostefano integrates all of these theoretical positions in his attempt to find an organizational context for his theorizing on the function of cognitive controls.

Like his predecessors, Santostefano makes effective use of factor analysis in his research. Employing some modificatons of methods and instruments originally used by the Gardner group, Santostefano is concerned with five cognitive control principles. In the volume cited above, he presents data from over a dozen separate studies designed to illustrate the uniqueness of each cognitive control and the validity and reliability of those tests designed to measure them. Like the Gardner group Santostefano believes that an understanding of the adaptive significance of cognitive controls as well as their hierarchical nature is central to understanding how cognitive controls and personality are related.

One of Santostefano's unique contributions to cognitive control literature is his development of cognitive control therapy. In general terms, cognitive control therapy is a variation of traditional psychotherapy. Upon the assessment and determination of a cognitive control deficiency, cognitive control therapy provides the individual with a specific sequence of perceptual kinesthetic experiences aimed at retracing those stages of cognitive development diagnosed as lagging. 
While the principle of leveling-sharpening is historically identified as one of several cognitive control principles. The present research does not seek to make any specific hypotheses or predictions about cognitive controls in general. Rather, it is only concerned with the phenomenon of leveling and sharpening and is limited to quantifying psychophysiological differences in attention between levelers and sharpeners. 
The Cognitive Control of Leveling and Sharpening

The principle of leveling/sharpening is concerned with the manner in which the individual manages information that remains stable but changes over time. Santostefano (1978) defines levelers as individuals who construct relatively global and unstable images of information, fusing the present information with past information so that information loses its discreteness. Sharperners are individuals who can maintain articulate and stable images of informaton. Thus, it is possible to differentiate present information from past information. The uniqueness of information is therefore maintained. The process of leveling-sharpening involves two independent components: 1) the ability to differentiate a memory image and 2) the ability to attend and maintain that image over time. It is important to make a clear distinction between cognitive control principles in general and those processes that are unique to the leveling-sharpening phenomenon. A cognitive control is a mechanism employed by 1 the individual that serves to mobilize and allocate those cognitive processes necessary for the effective and efficient management of information from the environment. It has been proposed that there are several cognitive controls, each one serving to mobilize and organize different types of cognitive processes. Thus, cognitive controls are collating mechanisms that serve to select and 
integrate those separate cognitive processes that are necessary to process environmental stimuli. The cognitive control process may be diagrammed as below : stimulus $\rightarrow$ sensation $\rightarrow\left|\begin{array}{l}\text { attention } \\ \text { concentration } \\ \text { sensory integration } \\ \text { spatial recognition } \\ \text { memory storage } \\ \text { memory retrieval } \\ \text { problem solving } \\ \text { abstract reasoning }\end{array}\right| \rightarrow$ cognitive control

Upon the reception of an environmental stimulus, a selection mechanism chooses those separate cognitive processes necessary to effectively deal with environmental stimuli and integrate them into an overall informational management strategy. It is this overall strategy, which is the sum of a variety of separate cognitive processes, that is a cognitive control. As the demands from the environment change so does the selection and integration of these separate cognitive processes. Thus, there are differing cognitive controls according to environmental demand. Leveling and sharpening is concerned with how quickly one can detect discrete changes among complex visual stimuli presented successively over many trials. The cognitive processes that are hypothesized to come into play during this process are memory and attention. The means by 
which these cognitive processes operate comprise a two step process. This is diagrammed below:

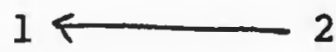

stimulus $\rightarrow$ sensation $\rightarrow$ attention $\rightarrow$ memory

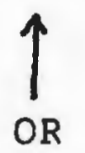

Step one is the attentional stage. A novel stimulus serves to draw one's attention to that stimulus. The physiological concommitant to this psychological event is the orientation response. During this attentional stage an internal representation of the physical stimulus parameters is created. For example, if the novel stimulus is a tone, the individual forms an internal representation of that tone in terms of its frequency ( $\mathrm{Hz}$ ) and intensity. If the novel stimulus is a picture of a house the internal model is composed of its various details, lines and graphics.

Step two is the memory-evaluation stage. This stage begins upon successive presentations of the stimulus. With each successive presentation of the stimulus the internal representation of that stimulus is re-evaluated in memory. This re-evaluation is necessary in order to judge whether or not there have been any changes in the stimulus. Thus, with each successive presentation a memorymatching process takes place. Using the Leveling-Sharpening House Test as an example the present stimulus (Card 2) is evaluated against the original stimulus (Card 1). The physical stimulus parameters created on Card 1 are used as a 
criterion reference against which later memory evaluations are made. When a change is detected the stimulus parameters of that card serve as a new criterion against which later memory-evaluations are made.

A variety of studies have been conducted that relate leveling and sharpening to other cognitive behaviors. A hypothesis that has been of particular interest is that levelers and sharpeners differ in the way novel stimuli are assimilated and maintained in memory. Holzman and Gardner (1959) found that when compared on a task of remote memory, levelers and sharpeners exhibited distinct quantitative and qualitative differences. Quantitatively, sharpeners exhibited superior remote memory recall. Qualitatively, the memory recall of levelers was distinctly more vague and disorganized than sharpeners.

In another experiment Santostefano (1978) found a relationship between the detection of the number of elements omitted on the Leveling-Sharpening House Task (LSHT) and the number of errors made on the Benton Visual Retention Test (BVRT). The BVRT consists of a series of 10 geometric designs. Each picture is displayed for 15 seconds, then the picture is removed and one is asked to reproduce it from memory. Both the LSHT and the BVRT presumably require the ability to maintain distinct memory images. It was found that levelers produced more errors on the BVRT and took longer to reproduce the designs than sharpeners. Other studies have examined the differences 
between levelers and sharpeners on attentional tasks. It has been hypothesized that sharpeners are superior to levelers in their ability to perceive and maintain fine distinctions between stimuli. When compared on their ability to differentiate between two stimuli of close but slightly different intensities Holzman (1954) and Holzman and Klein (1954) found that sharpeners demonstrated superior ability in this regard on a variety of visual and auditory discrimination tasks.

In another study, Israel (1970) was concerned with attentional differences between levelers and sharpeners in response to a boring and tedious task. The task used was a monotonous, 15 minute random generation task that consisted of punching either $D S$ or 1 s onto IBM cards. Subjects were instructed to be as random as possible. It was hypothesized that if sharpeners are better able to sustain attention, then they should be able to maintain a higher level of random behavior when instructed to randomly punch 0 s and is onto IBM cards. Results showed significant differences, with sharpeners exhibiting significantly more random behavior. However, on a self report measure levelers and sharpeners did not differ in their perception of the task as either "dull" or "easy." 
Leveling and Sharpening Under Affective Conditions

Several studies have been conducted that examine how the cognitive control of leveling and sharpening changes under stressful or affectively arousing conditions. Santostefano $(1983,1984)$ has stated that there is a bi-directional continuum which he termed the cognitive affective balance that determines how the cognitive control of leveling-sharpening changes under affectively arousing conditions. This continuum serves to reorganize leveling and sharpening either regressively (in the direction of increased leveling) or progressively (in the direction of increased sharpening) according to the demands of the environmental situation. The use of the terms progressive or regressive are not meant to connote a value judgment. Rather, either phenomenon is considered an appropriate adaptation under certain respective circumstances. Santostefano (1983) has hypothesized that there are two factors that determine whether or not and in what direction the leveling-sharpening principle will be re-organized. The first factor is the signal value of the stimulus or the degree to which one can actively use or incorporate to the demands of an affectively arousing situation. Leveling and sharpening is re-organized progressively towards increased sharpening when one actively attends to or incorporates the demands of an affectively arousing situation. Conversely, when one does not actively attend to or incorporate the demands of affectively arousing situation the cognitive 
control of leveling and sharpening is reorganized regressively (toward increased leveling).

The second factor that determines the re-organization of the leveling-sharpening principle is an individual's predisposition towards the affective situation in which the leveling-sharpening process is occurring. If the elements of an affectively arousing situation are relevant to an individual's common experience, then this will result in a progressive shift of the leveling-sharpening principle. Conversely, if the reverse is true a regressive shift in leveling and sharpening will take place.

Several studies have been conducted in support of this first factor. Guthrie (1967) administered two levelingsharpening tests to groups of parachutists. The tests administered were the Leveling-Sharpening House Test and the Leveling-Sharpening Parachute Test. These tests were administered while subjects were at home and again when they were at the airport immediately before a jump. The major finding concerns the difference in leveling and sharpening between these two locations. Subjects demonstrated a significant increase in sharpening while at the airport getting ready for a jump. Thus, the leveling and sharpening principle was reorganized progressively.

Shapiro (1972) obtained results in which the opposite phenomenon occurred. She studied three groups of children, two experimental groups and a control group. The first experimental group was due to undergo surgery for hernia 
repair and the second experimental groups was due to undergo cavity repair of a dental cavity at the dentist's for the first time. The Leveling-Sharpening House Test and the Leveling-Sharpening Hospital Test were administered on three occasions: at home one week before the surgical or dental procedure, immediately before the surgical or dental procedure, and three weeks later at home. Results for the two experimental groups showed a regressive shift towards leveling on the latter two test occasions in relation to the controls. Also, the surgical group demonstrated more leveling than the dental group.

Santostefano (1983) has stated that the context in which a stimulus occurs may be viewed as a call for action, i.e., a prescription for eliciting particular motor and cognitive responses and emotions. Thus, a presumably affectively arousing stimulus (such as the parachute or hospital test) will elicit fantasies and thoughts that are either representative of, or at least related to, an individual's past or expected experience with these situations. For example, the parachute test administered minutes before the parachutist takes off for a jump should elicit fantasies and thoughts concerning the impending dangerousness of the jump. If the leveling-sharpening principle is viewed as a mechanism that coordinates an appropriate cognitive response to the fantasies elicited by a particularly meaningful affectively arousing stimulus, then it is reasonable to expect that an adjustment will be 
made in the cognitive control that will serve the adaptation needs of the individual. Hence, during a heightened drive state Guthrie found that the parachutists sharpened in response to an affectively arousing stimulus. Such a response is appropriate in serving the immediate adaptation needs of these individuals at this particular time. If the parachutists leveled in response to this affectively arousing stimulus one might interpret this response as a denial of the implicit dangerousness of the situation. Such denial would be inappropriate in this context and would not serve the adaptation needs of the situation and would be cause for great concern.

In light of this reasoning, how can we view the tendency of Shapiro's surgical and dental groups to level in response to their respective affectively arousing situations? How does leveling serve the best adaptable interests of these children? As stated above, Santostefano (1983) states that the reorganization of the levelingsharpening cognitive control depends upon the degree to which the individual can engage in active information gathering concerning specific, external affectively arousing situations. If the external situation permits the individual to actively participate and incorporate into his or her cognitive processing the elements of this situation, the cognitive control is expected to shift to the active registration and incorporation of those important elements inherent in external situations. Such active participation 
is expected from the parachutists. However, children who are going to the hospital or dentist for an aversive procedure over which they have no control, may not be expected to participate actively in registering and incorporating elements of these situations. These procedures are at least invasive if not aversive in nature. Hence, leveling could be viewed as is the appropriate adaptation response.

The second factor that may either contribute to or help determine the re-organization of the levelingsharpening principle is an individual's predisposition to the affectively arousing stimulus. In two separate studies, Santostefano $(1983,1984)$ separated children into high or low aggressive groups by means of their response to card 18MF from the TAT and the Miniature Situations Test (MST). The tests administered were the Leveling-Sharpening House Test and the Leveling-Sharpening Aggression Test. The results showed that across groups the high aggressive children tended towards increased sharpening on the Leveling-Sharpening Aggression Test as compared to the Leveling-Sharpening House Test while the low aggression group demonstrated the opposite behavior.

Pavlov (1927) argues that for a stimulus to have optimal meaning for the individual, the stimulus must be able to elicit from the organism an immediate investigatory response that results in a full evaluation of the ecological significance of the stimulus. Such a factor may explain the 
leveling and sharpening behavior of Santostefano's low and high aggressive children. For the low aggressive children, the affectively arousing situation portrayed in the aggression test may not be related to their usual experience or environment. Therefore, the test is of little meaning for these children and does not elicit an active incorporation of the elements of this test into the reorganization of their leveling and sharpening behavior. Thus, the leveling and sharpening principle is reorganized regressively or not at all. For the high aggressive children, the affectively arousing situation may very much be related to their usual environment. For these children, psychological issues related to aggression might be an integral aspect of their overall personality functioning. Therefore, it is not surprising that these children would orient themselves towards and be willing to participate in the active incorporation of elements from this task. Thus, there is good reason to expect that the leveling and sharpening principle would be reorganized progressively as a reflection of the highly meaningful nature of the stimulus. 
The Orientation Response

The psychophysiological behavior of particular interest here is the orienting response (OR). Originally introduced by Pavlov (1927) and later extensively researched by Sokolov (1963), the OR is thought to be a response mechanism possessing much ecological importance for the organism. Pavlov writes that the function of the OR is "to bring about the immediate response in man and animals to the slightest changes ... around them so they immediately orient their appropriate receptor-organs in accordance with the perceptible quality... about the change, making full investigation of it" (Pavlov, 1927). Although Pavlov was able to articulate and describe this construct he never conducted a full investigation into its properties and parameters. However, it is clear that Pavlov believed that the overall function of the $O R$ is as a mechanism having great signal value to the organism, helping it to adapt to its environment.

More recently, the phenomenon of the OR has come under detailed study through the research of Ye. N. Sokolov (1960a, 1960b, 1963). Concurring with Pavlov, Sokolov describes the $O R$ as a signal device which, under optimal conditions activates the appropriate attentional and information seeking receptor processes when the individual is confronted by a novel stimulus configuration possessing collative properties (Berlyne, 1963). In actuality, sokolov describes two separate response systems that may occur as 
the result of exposure to a stimulus configuration possessing collative properties, the orientation response and the defensive reaction (DR). The $O R$ is viewed by sokolov as an independent functional system which is defined by the following criteria: an $O R$ is elicited by a stimulus of moderate to low intensity; a specific pattern of vascular responding occurs including peripheral vasoconstriction and cephalic vasodilation; there is rapid habituation to repeated stimulation; and the same pattern of response to both onset and offset of stimulation takes place. The defensive reaction is defined by the opposite criteria listed above: a DR is elicited by a stimulus of high intensity; there is a pattern of simultaneous peripheral and cephalic vasoconstriction; an intensification over repeated stimulation takes place; and there is an irregular pattern to both onset and offset of stimulation (Sokolov, 1963a). However, subsequent research has not been able to completely and consistently uphold sokolov's distinction between the $O R$ and the DR. While some researchers have reported a clear differentiation between these two response systems (Hare, 1972) others have reported either ambiguous results (Raskin, Koates, and Beaver, 1969) or have failed to illustrate the distinction at all (Geer, 1969).

A possible reason why Sokolov's two response systems have failed to be consistently demonstrated may lie in the nature of the stimulation used in these experiments. In almost every case the research described above employed 
simple sensory stimulation of nonsignal value. A point emphasized by both Pavlov and Sokolov is the importance of the signal value of the stimulator causing the orientation response. As stated above, the function of the OR is to alert the organism to the possible functional significance of environmental stimulation.

Bernstein (1969, 1975) was particularly interested in just this issue. He argues that research employing stimuli of low signal value may artificially lower a subject's motivational level. Thus, the evaluation of the ecological significance of the stimulation is altered. He found consistently greater orientation responses were elicited by stimulation which had relatively high signal value than by concomitant physically identical stimuli of no signal value. Similarly, Berlyne (1963) noted that the frequency of orienting responses to complex visual patterns increased when subjects were told they would be tested later on their ability to recognize these stimuli.

While the distinction between the $O R$ and the $D R$ has not consistently been upheld, the notion that the OR is a device that facilitates the intake and processing of information from the environment is widely upheld. In a review article Graham and Clifton (1966) examined much of the literature concerning the $O R$ as operationalized by cardiac activity. They concluded that the description and function of the $O R$ as articulated by sokolov (1963) is compatible with the Laceys' (1980) contention that heart 
rate deceleration is a physiological concomitant behavior with the psychological attentional processes. 
The OR: Psychological Correlates

Cardiac activity has been widely employed as a psychological measure. Siddle and Graham (1980) state that this popularity may be traced to two factors. First, the technigues for recording heart rate are derived from medicine; thus they have been readily available and accepted as an important physiological index. Second, cardiac activity has been associated with psychological and physiological theories of arousal. Cannon (1929) put forth the notion that cardiac activity is an index of a generalized physiological response which accompanies psychological changes in arousal. This physiological response was thought to prepare, enhance or otherwise facilitate an increased behavioral drive in response to some external stimulus. Duffy (1962) termed this particular interpretation of Cannon's arousal hypothesis "energy mobilization."

However, viewing cardiac activity as a unidirectional, linear, or diffuse measure of arousal has proven to be a naive interpretation. Observations of differential cardiac response systems began to suggest that there were differences not only in the physiological pattern of heart action, but that these differing physiological patterns were related to the nature, content, and demands of the psychological stimulation to which the individual was subjected. For example, as early as 1929, at the time Pavlov was speaking of the ecological significance of the OR, Darrow observed heart rate deceleration when subjects were required 
to attend to simple stimuli and heart rate acceleration when subjects were subjected to intense or threatening stimuli, engaged in mental arithmetic, and during periods of word association. This bi-directional nature of cardiac change in response to environmental demands clearly indicates that the simple arousal interpretation in which changes in cardiac activity are viewed in terms of energy mobilization is by far too unsophisticated.

The most influential work concerning the bidirectional response of cardiac activity to psychological stimulation has been conducted by John and Beatrice Lacey (1970, 1978, 1980). The Laceys, like the Russian investigators, also believe that orientation response systems have an important ecological function within the greater scheme of information processing. Their formulations were made while observing cardiac responses during stimulus presentation. The phenomenon they have observed is called directional fractionation. This phenomenon centers around a differential operation of cardiac activity varying according to the type of cognitive processing in which the individual is engaged. More specifically, the directional fractionation hypothesis asserts that heart rate deceleration will be observed during situations requiring the incorporation of stimulation from the environment and heart rate acceleration will be observed during situations requiring the rejection of stimulation from the environment. The Laceys believe that the presence of cardiac deceleration 
is not just an associational component of attention or environmental intake per se; rather heart rate deceleration is viewed by the Laceys to be fundamentally involved in the facilitation of sensory processing itself. Likewise, heart rate acceleration is viewed as leading to the inhibition of sensory processing.

The Laceys administered a variety of tasks and measured cardiac activity while subjects were actively engaged in these tasks. Heart rate decelerations occurred when subjects were required to attend to visual or auditory inputs, while heart rate acceleration occurred when subjects were required to engage in problem solving tasks such as mental arithmetic problems.

This work has culminated in the formulation of a model in which cardiac responding indirectly alters cortical activity by means of a visceral afferant feedback system that is mediated by baroreceptors (Lacey, 1967, 1978). This theoretical model has stimulated much research. While the specific nature of the Lacey's baroreceptor feedback system has been questioned (Obrist, Webb, and sutterer, 1969), the bi-directional phenomenon of cardiac responding in relation to differing enviornmental demands has had consistent support in the literature Cobrist and Webb, 1970 ; Tursky, Schwartz and Crider, 1970 and Spence, Lugo and Youdin, 1977).

The strategy normally employed in this type of research has been to show a relationship between the various 
parameters of cardiac reactivity and performance on some task of information processing. For example, Maltzman and Mandell (1968) found that those subjects performing significantly better on a test of semantic generalization also exhibited a significantly greater magnitude of the OR. Zeiner and schell (1971) found that subjects demonstrating significantly better learning and faster conditioning also demonstrated a significantly higher magnitude of the OR. Cousin (1977) showed that when subjects were separated into groups of fast or slow learners, the fast learners exhibited a significantly higher magnitude of orienting behavior. Lewis and wilson (1970) showed a significant relationship between the $O R$ and correct responding on a matching figure test.

As stated above, the only psychophysiological studies of leveling and sharpening that have been conducted have been carried out by Israel. In her first study, Israel (1966) stated that a major distinction between levelers and sharpeners is the rate in which novel stimulation is assimilated and maintained. She hypothesized that levelers should assimilate novel stimulation more quickly than sharpeners. Thus, it was predicted that sharpeners would take longer to habituate during a perceptual-assimilation task than levelers. Habituation was defined as the number of GSR - OR's over a 13 block trial period. Israel employed a two-step procedure. First she measured GSR-OR during her perceptual task; then she identified subjects as either 
levelers or sharpeners using the Gardner et al. (1959) procedure. The results confirmed Israel's expectation. Sharpeners habituated more slowly and displayed a greater number of GSR-ORs than levelers.

In her second study, Israel (1969) looked at heart rate $O R$ and levelers and sharpeners in response to stimuli they had rated as very interesting, not very interesting, or potentially anxiety provoking. On the basis of the Laceys' directional fractionation hypothesis, it was predicted that levelers would show either little cardiac change or heart rate acceleration on anticipation of low preference and anxiety stimuli. Sharpeners would show heart rate deceleration regardless of the type of stimulation. The task used in this experiment consisted of five blocks of geometric figures - two simple and two complex. Between the fourth and fifth block of stimuli, a slide of a nude woman was shown. This was presumed to be anxiety provoking. The experimental trials always consisted of the two blocks of simple figures presented first followed by two blocks of complex figures. After the nude was presented the fifth trial block consisted of the same stimuli presented in block two.

Again, the results supported Israel's hypothesis. When analyzed across the first four blocks of trials, irrespective of stimulus preference there was no difference between groups. After the nude, however, levelers displayed significant HR acceleration, whereas sharpeners maintained 
HR deceleration. When analyzed with regard to stimulus preference, sharpeners continued to show HR deceleration regardless of stimulus preference whereas levelers exhibited HR deceleration only with high preferred stimuli.

These findings demonstrate very consistent covariations between the $O R$ and a wide range of cognitive, information processing behaviors and would seem to suppport the bi-directional hypothesis. The relationship between superior performance on cognitive tasks and the magnitude of the $O R$ is consistent. On the basis of this relationship, it is reasonable to assert that the OR serves some broader function that may be observed regardless of the specific contingencies of the type of cognitive task imposed by the environment.

The research conducted by the Laceys and others would seem to support Sokolov's interpretation that the OR has important ecological significance in directing the individual's attention to the salient qualities of environmental stimulation. Furthermore, their observation of the bi-directional nature of cardiac responding increases the significance of the phenomenon of the OR. The research conducted by the Laceys, as well as other results reported above showing a positive relationship between the magnitude of the $O R$ and cognitive performance, indicates that the $O R$ plays an active role in the facilitation and subsequent processing of incoming environmental stimulation. On the basis of these results, it may be concluded that the OR 
plays a crucial role in cognitive processing and that the $O R$ is a physiological mechanism that acts to simultaneously marshall and direct the impetus for action when the individual is exposed to novel stimulation. 


\section{Hypotheses and Predictions}

This research had two hypotheses. The first hypothesis concerns the relationship between attention and cognitive control. It was hypothesized that levelers and sharpeners would differ significantly in attention and that it is this attentional difference that would determine the degree of leveling and sharpening behavior. In this research attention is operationalized psychophysiologically by means of the orientation response. On the basis of this hypothesis, the following prediction was made:

1) It was predicted that on the LSHT sharpeners would exhibit greater orientation responses than levelers. However, a significant higher order interaction may modify the interpretability of such a finding.

The second hypothesis concerned how these attentional differences between levelers and sharpeners would be altered by changes in the signal value of the two leveling-sharpening tasks and a subject's predisposition towards the trait of aggression. It is hypothesized that if attention accounts for a significant difference between levelers and sharpeners, then this difference should be further elucidated when attention is measured across tasks of differing signal value. If the OR observed during the neutral leveling and sharpening task (LSHT) can be viewed as a baseline measure of attention, one should expect a consistent shift in attention both when the signal value of the levelingsharpening task is altered to be affectively arousing (LSAT) 
and when one takes into account a subject's predisposition towards aggression. On the basis of this hypothesis the following predictions were made:

2) The second prediction was that the affective task (LSAT) would differentially affect attention so that one would observe an increase in orienting behavior among sharpeners and either no change or decrease in orienting behavior among levelers. This prediction would be supported by a significant two-way interaction between levelerssharpeners and the two leveling-sharpening tasks.

3) The third prediction was that a subject's predisposition towards the trait of aggression would further differentiate levelers from sharpeners as measured by heart rate orienting behavior. This prediction would be supported by a significant interaction among all three independent variables. It was predicted that high aggressive subjects (as measured by the EPPS) who were sharpeners (as measured by the LSHT) would exhibit the highest magnitude orienting behavior followed by low aggressive sharpeners, high aggressive levelers, and low aggressive levelers. 
Method

\section{Subjects:}

Sixty introductory psychology students were used in this research. Research participation was a partial fulfillment of their course requirements. Subjects were selected at random from a pool of volunteers.

\section{Instruments:}

Two tasks were employed: the Leveling-Sharpening House Task (LSHT), Fig. 1, and the Leveling-Sharpening Aggression Task (LSAT), Fig. 2. Both of these tasks were devised and used by Santostefano (1978, 1983). The former task is neutral in content while the latter task is designed to be affectively arousing. Both tests consist of 60 cards, $81 / 2$ by 11 inches, and six practice cards. The house test cards present a scene of a house drawn three-dimensionally in black and white. With the presentation of the first three cards all details of the picture are preserved. Beginning with the fourth card, one of the details (doorknob) drops out. With the presentation of every third card after Card 4, one additional detail is omitted. Thus, on Card 7 , not only the doorknob but a fence board is omitted. Table 1 and Table 2 ist all of the details that are omitted and the scoring key for correct changes perceived for each test. The aggression task depicts an antique western scene of two men facing each other in front of a saloon engaged in a gun 
fight. In both tasks, all details of the picture are preserved for the first three cards. Beginning with the fourth card, one detail drops out with successive details dropping out every third card.

As stated above, the aggression scale from the Edwards Personal Preference Schedule (Edwards, 1959) was used to divide subjects into high and low aggression groups. This was done by means of a median split.

\section{Procedure:}

Each trial corresponded to the presentation of one of the sixty cards in both Leveling-Sharpening tasks. Each trial consisted of three segments (Fig. 3) The first segment was a 10-second baseline period in which the subject was instructed to sit quietly and engage in no mental activity. The second trial segment began with a warning tone $(70 \mathrm{db}, 1000 \mathrm{hz})$ on the 11 th second and was five seconds in length. The subject was instructed that the tone signaled the impending onset of the stimulus presentation and that the subject should prepare for this. The third trial segment, beginning on the 16 th second, consisted of the stimulus presentation. Following Santostefano (1978), each card was presented for five seconds. The subject was instructed to respond following santostefano's procedures. 
Trial Segment: LSHT

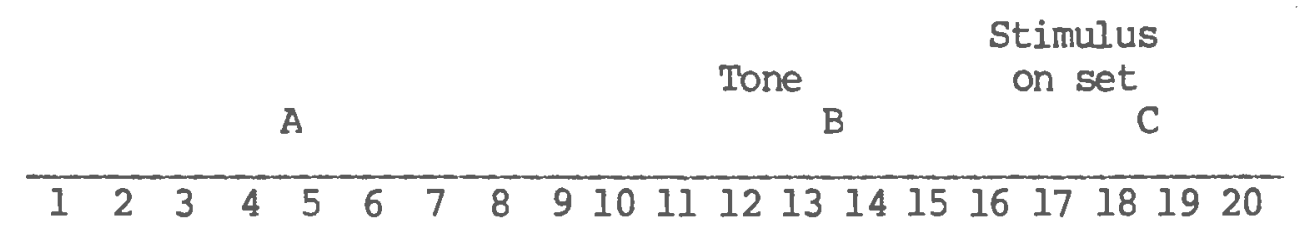

Trial Segment: LSAT

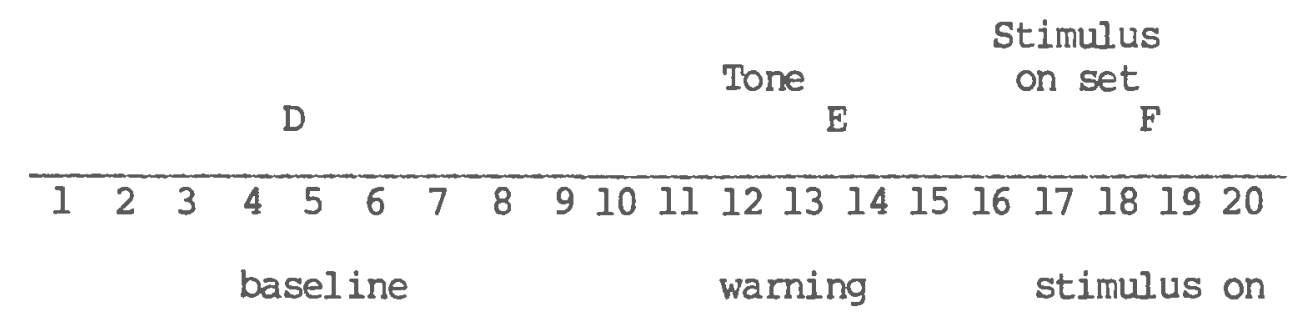

igure 3

rial segments for the LSHT and LSAT 
As each subject entered the laboratory, he/she was seated in a comfortable arm chair. The examiner explained the nature of the research to the subject. AG/AGCL electrodes were attached and the subject was given ten minutes to acclimate him/herself to the room and the equipment. Testing began with the six practice cards which depict a Christmas tree. During this practice session the subject was instructed as to the meaning of the warning tone and how to do the Leveling-Sharpening task. The specific instructions given to the subject during each of the three trial segments are contained in Appendix A.

After the initial practice phase, which is conducted with the six practice cards, the test phase begins. The subject is told that the pictures will be seen one at a time. The subject is also told to look at the pictures carefully and is told that "if any of the pictures look different or something looks like it changed, say stop". The subject is further instructed to say nothing if "the pictures look the same." Each card is presented for five seconds.

\section{Data Analysis:}

This research includes three independent variables: EPPS aggression (high and low), cognitive control (levelers and sharpeners), and task (neutral and affective leveling and sharpening tasks). The leveling-sharpening ratio on the LSHT 
described above will be used to define subjects as levelers or sharpeners by means of a median split.

Two dependent variables were used in this research:

heart rate and the leveling-sharpening first stop scores. The first stop score is the card number on which the first correct change is perceived. The leveling-sharpening ratio is given as :

\# opportunities to perceive each change for each detected change,

+ \# opportunities subject had to detect change

LS ratio $=$

\section{9 (total \# omitted details)}

The earlier the subject perceives a change, the smaller the value of the first stop score and the greater the number of changes detected, the smaller the ratio. Small L/S ratios indicate sharpening.

Heart rate was recorded by a cardiotachometer which converts each EKG $R-R$ interval to a beat-per-minute score. Standard bi-polar leads were used with right leg as ground.

The OR was defined as follows: the mean heart rate in the warning trial segments ( $B$ and E, Fig. 3), was subtracted from the mean heart rate during the last five seconds in the baseline trial segments ( $A$ and $D$, respectively). This difference score is an index of cardiac deceleration or acceleration. A score of zero indicates no change from baseline to the warning periods. A negative score indicates heart rate deceleration whereas a positive score indicates 
heart rate acceleration.

All these predictions were tested by means of a 2 (leveling-sharpening) x 2 (high/low EPPS-aggression) $\times 2$ (tasks) 3-way ANOVA (Kirk, 1968) with repeated measures on the last factor. Simple two-way interaction effects were analyzed according to procedures described by Keppel (1973). For each leveling-sharpening task, separate Mann-Whitney tests (Marasculo and McSweeny, 1977) were conducted to assess differences between levelers and sharpeners on the first stop scores. Finally, a Pearson correlation between the two leveling-sharpening ratios and a spearman correlation between the two first stop scores and leveling-sharpening ratios for the LSHT and LSAT were conducted to assess the relationship between the two leveling-sharpening tasks. 
Results

Sixty subjects were tested, and 12 were eliminated due to heart rate artifact. Subjects were eliminated if more than 10 trials on either leveling-sharpening task had to be rejected due to movement artifact. Raw data for the remaining 48 subjects is 1 isted in Appendix B. The 24 sharpeners are listed first followed by the levelers.

The means, standard deviations, and ranges of scores for all variables and for all subjects are listed in Table 4 . For the heart rate scores a negative score signifies heart rate deceleration and a positive score heart rate acceleration. The first stop score signifies the trial upon which subjects first noticed a change in stimulus presentation. The score for the EPPS aggression scale is given as a percentage rank. The means, standard deviations, and ranges for all scores are listed separately for levelers and sharpeners in Tables 5 and 6.

All three predictions were tested by means of a 2 (leveler-sharpener) x 2 (high-low EPPS Aggression) $x 2$ (LSHT-HR/LSAT-HR) ANOVA with repeated measures on the last factor. A test for the homogeneity of variance for heart rate change scores gave a statistically significant result, $F$ max $(8,11 \mathrm{df})=7.90, \mathrm{p}>.05$. 
Table 4:

Means, Standard Deviations and Ranges for All Variables

Blocking Variables

Mean

$S D$ Range

L/S Ratio (House)

L/S Ratio (Agg)

Edwards Aggression
13.6

19.2

42.0

Mean

$S D$

Range

Heart Rate (House)
$-0.29$

0.17

11.7
21.8
2.5

4.2

26.5

01

$$
6.8-19.4
$$$$
9.8-25.5
$$

$-95$
Heart Rate (Agg)

First Stop Score (House)

First Stop Score (Agg)

Dependent Variables
0.55

$-1.65-0.80$

0.97

$-3.13-2.20$

5.4

04

8.7

07
$-25$

$-34$ 
Table 5:

Means, Standard Deviations and Ranges for All Variables (Sharpeners, $\mathrm{N}=24$ )

Blocking Variables Mean $S D$ Range
L/S Ratio (House)
11.7
1.58
$6.8-13.6$
L/S Ratio (Agg)
17.5
4.62
$9.8-23.5$
Edwards Aggression
42.0
24.77
01
$-95$

Dependent Variables Mean $S D$ Range

Heart Rate (House)

$-0.39$

0.53

$-1.65-0.50$

Heart Rate (Agg)

0.23

0.88

$-2.18-2.20$

First Stop Score (House)

9.8

3.75

$04-19$

First Stop Score (Agg)

18.6

9.02

07

$-29$ 
Table 6:

Means, Standard Dexiations and Ranges for All Variables (Leveler, $\mathrm{N} \equiv 24$ )

Blecking Variables Mean SD Range

$\begin{array}{llccc}\text { L/S Ratio (House) } & 15.2 & 1.69 & 13.8 & -19.4 \\ \text { L/S Ratio (Agg) } & 20.9 & 2.97 & 14.1 & -24.9 \\ \text { Edwards Aggression } & 42.0 & 30.70 & 02 & -84\end{array}$

Dependent Variables Mean SD Range

$\begin{array}{lcccc}\text { Heart Rate (House) } & -0.19 & 0.58 & -1.12-0.80 \\ \text { Heart Rate (Agg) } & 0.12 & 1.12 & -3.13-1.82 \\ \text { First Stop Score (House) } & 13.6 & 6.16 & 10 & -25 \\ \text { First Stop Score (Agg) } & 24.3 & 6.63 & 13 & -30\end{array}$


No transformation was applied to the data because the level at which this test was significant was marginal and because there was no systematic relationship between cell means and standard deviations ( $r=$ n.s.). The source table for the 3-way, repeated measures ANOVA is in Table 7 and indicates that the leveling-sharpening $x$ EPPS-Aggression $x$ Task interaction is significant, $F(1,44)=4.89, p<0.05$. All means and standard deviations for this analysis are listed in Table 8 and graphically depicted in Figure 4. The simple 2-way interactional analyses showed that for low aggression subjects there was a main effect for task, $F(1,22)=6.29, \mathrm{p}<.05$ (LSHT MHR $=-0.36$, LSAT MHR $=$ 0.17 ) and a significant task $x$ cognitive control interaction, $F(1,22)=5.84, p<.05)$. For sharpeners, there was also a significant main effect for task, $F(1,22)=9.98, p<$ .001 (LSHT MHR $=-0.42$, LSAT MHR $=0.26$ ). Post hoc analyses conducted with Tukey Tests on the 3-way repeated measures analysis (Winer, 1971) indicated that the sole significant pairwise difference between conditions was the difference in heart rate of low EPPS-Aggression sharpeners between the House Test and Aggression Test (MHR-LSHT $=-0.61$ vs. M HR-LSAT $=0.45)$.

The prediction tested by the 3-way, repeated measures ANOVA was that high EPPS-Aggression Sharpeners would show the highest magnitude of heart deceleration and that low EPPS-Aggression levelers would show the highest magnitude in 
heart rate acceleration between the two leveling-sharpening tasks. Although this interaction was significant, heart rate change scores were not in the direction predicted. The repeated measures, 3-way ANOVA did indicate a significant main effect only for task, $F(1,44)=9.93, p<.001$. An examination of Table 8 shows that regardless of whether subjects are levelers or sharpeners or scored high or low on the EPPS-Aggression Scale, heart rate shifted from deceleration on the LSHT $(M=+0.29)$ to acceleration ( $M=$ +0.18 ) on the LSAT. Thus, in general on the neutral LSHT, subjects exhibited an orientation response of low magnitude, whereas on the affectively arousing LSAT, no orienting behavior was observed.

The simple effect analyses reported above also failed to uphold the other predictions of this experiment. It was predicted that on the LSHT sharpeners would exhibit greater heart rate deceleration than levelers, however, the simple effects analyses failed to show any differential effect on heart between levelers and sharpeners. Also, it was predicted that a change in the signal value of the leveling/sharpeners tasks (e.g., from the LSHT to the LSAT) would cause greater heart rate deceleration among levelers. However, this was not upheld.

Two separate Mann-Whitney tests were conducted to assess differences between levelers and sharpeners on the first stop scores. On the LSHT, the difference in mean 
ranks was not significant (sharpeners $=21.5$ vs. levelers $=$ $27.5, z=1.73$ n.s.). On the LSAT, the difference in mean ranks was significant (sharpeners $=19.5$ vs. levelers = $29.4, \mathrm{Z}=2.47, \mathrm{P}(.01)$.

A series of correlational analyses was conducted to assess the relationship between the two leveling-sharpening tasks. The product moment correlation was significant, $r=$ 33, p $<.001$. A spearman correlation between the LSHT first stop score and LSAT first stop score, however, was not significant, rho $=0.12$, n.s. Finally, a spearman correlation between the leveling-sharpening ratio and the first stop score on the LSHT was significant, rho $=.44, p<$ .001, as was the spearman correlation between the levelingsharpening ratio and first stop score on the LSAT, rho = $.78, p<.001$. While these analyses as well as the MannWhitney analyses are not directly related to any of the predictions described above, their importance will be discussed below. 


\section{Table 7:}

Source Table for 2 (Leveling-Sharpening) × 2 (High/Low EPPS-Aggression) × 2 (LSHT-HR/LSHT-HR) Repeated Measures ANOVA with Heart Rate as Dependent Variable

$\begin{array}{lrrcc}\text { Source } & \begin{array}{c}\text { Sum of } \\ \text { Squares }\end{array} & \text { DF } & \text { Mean Square } & \text { F-Test } \\ \text { Mean } & .21201 & 1 & .21201 & .36 \\ \text { Leveling-Sharpening } & .07956 & 1 & .07956 & .13 \\ \text { Aggression } & .20664 & 1 & .20664 & .35 \\ \begin{array}{l}\text { Leveling-Sharpening } \\ \quad \text { x Aggression }\end{array} & .24191 & 1 & .24191 & .41 \\ \begin{array}{l}\text { Error } \\ \text { Task }\end{array} & 26.10859 & 44 & .59338 & \\ \text { Task x Leveling-Sharpening } & 6.59237 & 1 & 6.59237 & 9.93 * \star \\ \text { Task x Aggression } & .55363 & 1 & .55363 & .83 \\ \text { Task x Aggression x } & .00558 & 1 & .00558 & .01 \\ \quad \text { Leveling-Sharpening } & 3.24572 & 1 & 3.24572 & 4.89 * \\ \begin{array}{l}\text { Error } \\ \quad 29.22339\end{array} & 44 & .66417 & \end{array}$

Note: * denotes statistical significance at the .05 level ** denotes statistical significance at the .001 level 
Table 8 :

Means and Standard Deviations for Heart Rate Change Scores for High and Low Aggression Subjects on the

Leveling-Sharpening House Test and the Leveling-Sharpening Aggression Test

\section{LSHT}

EPPS-Aggression

\begin{tabular}{|c|c|c|c|}
\hline & Low & High & \\
\hline Sharpeners & $\begin{array}{l}-0.61 \\
(0.588)\end{array}$ & $\begin{array}{l}-0.23 \\
(0.433)\end{array}$ & -0.39 \\
\hline \multirow[t]{4}{*}{ Levelers } & $\begin{array}{l}-0.13 \\
(0.608)\end{array}$ & $\begin{array}{l}-0.29 \\
(0.568)\end{array}$ & -0.19 \\
\hline & -0.33 & -0.25 & -0.29 \\
\hline & \multicolumn{2}{|c|}{$\begin{array}{c}\text { LSAT } \\
\text { EPPS-Aggression }\end{array}$} & \\
\hline & Low & High & \\
\hline Sharpeners & $\begin{array}{c}0.46 \\
(0.542)\end{array}$ & $\begin{array}{c}0.07 \\
(0.976)\end{array}$ & 0.25 \\
\hline \multirow[t]{2}{*}{ Levelers } & $\begin{array}{l}-0.11 \\
(1.217)\end{array}$ & $\begin{array}{c}0.45 \\
(0.929)\end{array}$ & 0.12 \\
\hline & 0.13 & 0.23 & 0.18 \\
\hline
\end{tabular}




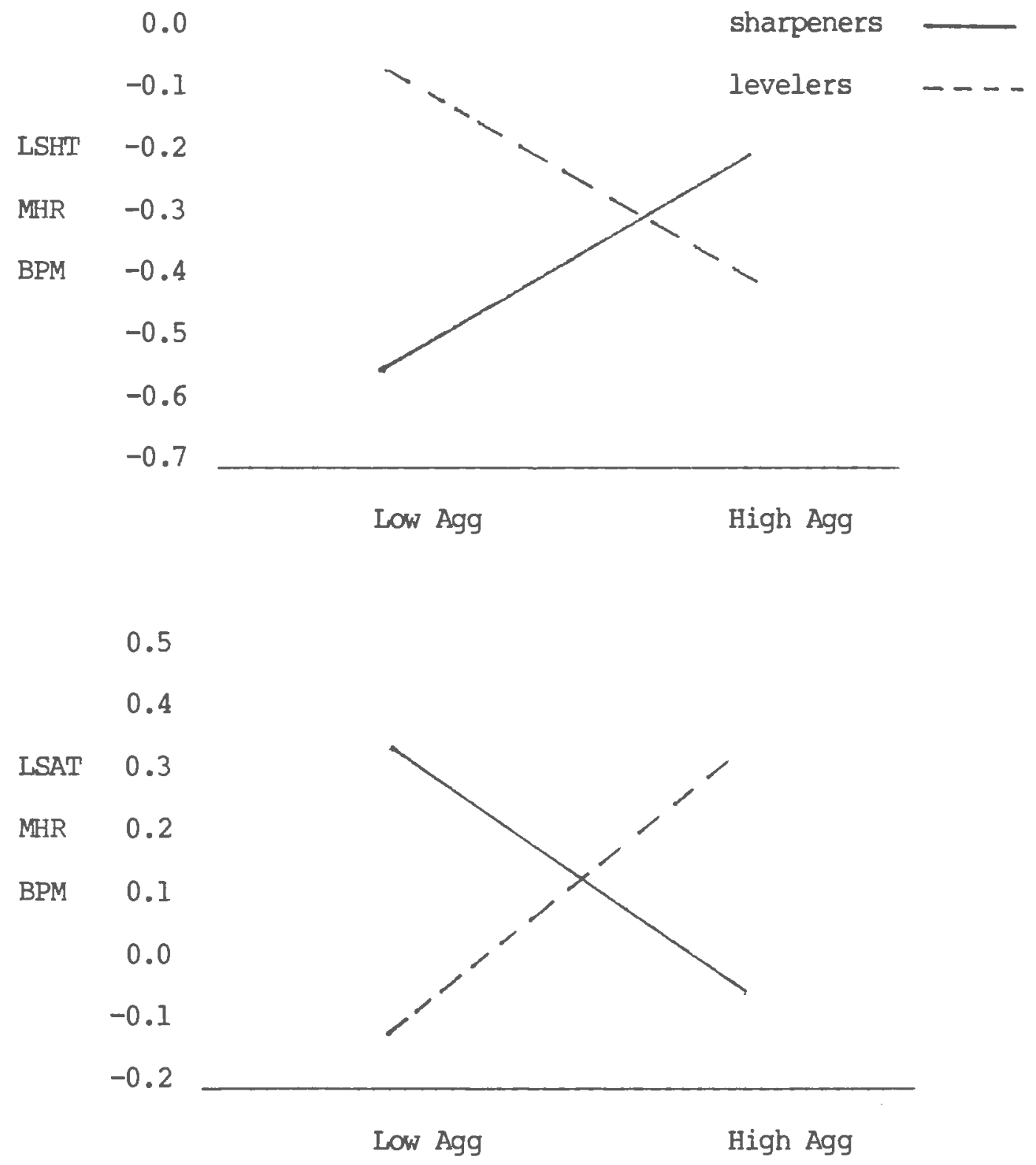

Figure 4:

Heart Rate Change for Low and High EPPS-Aggression Subjects on the Leveling-Sharpening House Test and the Leveling-Sharpening Aggression Test 
Discussion

The major hypothesis in this research was that the most important cognitive distinction between levelers and sharpeners is in their utilization of attention. This hypothesis is implicit given the nature of levelingsharpening tasks and has been tested indirectly by Holzman (1954) and Holzman and Klein (1954). The present experiment sought to obtain direct evidence for this hypothesis by showing a relationship between leveling-sharpening and the orienting response, an accepted psychophysiological measure of attention. Thus, the first prediction in this research was that on the LSHT sharpeners would exhibit a more pronounced orientation response which is indicated by greater heart rate deceleration. Although both groups exhibited orienting behavior, they did not differ significantly. Thus, on the basis of this analysis, it must be concluded that this experiment failed to prove that there is an attentional difference between levelers and sharpeners which can be detected by heart rate measures.

The second hypothesis was that a change in the signal value between leveling-sharpening tasks would result in concomitant changes in attention that would be reflected in differing patterns of orientation responses between levelers and sharpeners. This hypothesis sought to test Santostefano's (1983) idea that the context in which a stimulus occurs places different cognitive demands upon the 
individual which are then reflected in changes in the leveling-sharpening process. Thus, the second prediction in this research was that there would be a significant two-way interaction between cognitive control (leveling/sharpening) and task (LSHT/LSAT) with sharpeners exhibiting greater heart rate deceleration on LSAT than on the LSHT. The failure of this interaction to reach statistical significance and the relative shift from heart rate deceleration on the LSHT to heart rate acceleration on the LSAT indicates that a change in context by itself was not enough to differentiate the hypothesized attention differences between levelers and sharpeners.

The third prediction sought to examine how an individual's predisposition to the trait of aggression would affect the leveling-sharpening process. This prediction sought to test Santostefano's (1983) notion that an individual's predisposition to incorporate or reject affective stimuli alters the leveling-sharpening principle. This alteration in leveling-sharpening depends upon the fantasies elicited by a particularly meaningful affective stimulus. Thus, it was predicted that as subjects went from the LSHT to the LSAT, the high EPPS-Aggression sharpeners would exhibit the most pronounced difference, indicating increased sharpening (manifested by more pronounced heart rate deceleration) and the low EPPS-Aggression levelers would show the converse trend, indicating increased leveling (manifested by more pronounced heart rate acceleration). 
In this experiment it was predicted that because low EPPS-Aggression subjects are unconcerned with aggressive ideation when these subjects are asked to actively engage in a leveling-sharpening task that contains an aggressive theme, their responses might not differ much from what they were on the neutral task. Therefore, it was predicted that high EPPS-Aggression sharpeners would show the most pronounced changes in leveling-sharpening behavior on the LSAT.

The repeated measures analysis used to test this hypothesis indicated that there was no group difference in heart rate orienting behavior between either levelers or sharpeners on high/low aggression groups. There was a main effect for task. This means that again regardless of whether a subject was a leveler or sharpener or scored high or low on the EPPS, heart rate went uniformly from deceleration on the LSHT to acceleration on the LSAT and that on the LSAT, subjects on the average tended not to exhibit an orientation response.

Although the three-way interaction was significant, the direction of the shift in heart rate from the LSHT to the LSAT was not as predicted. It was predicted that high EPPS-Aggression sharpeners would show the highest magnitude of heart deceleration and that low EPPS-Aggression levelers would show the highest magnitude of heart rate acceleration on the LSAT. What occurred is a general trend toward heart acceleration among all four groups. 
The follow-up analyses indicated that the statistical significance of this three-way interaction is accounted for by a difference in heart rate between leveling-sharpening tasks among the low EPPS-Aggression sharpeners which was not as predicted.

An important question to be addressed is whether leveling and sharpening are accurately measured in this study. When one compares the distribution of levelingsharpening ratios obtained in this research to distributions reported elsewhere it is readily apparent that the range of leveling-sharpening ratios obtained in this research is consistent with the other previously reported experiments where the LSHT was administered to adult populations. For example, Guthrie (1967) reported a range of scores on the LSHT between 7.7 and $20.6(M=12.5)$ and Shapiro (1973) reported a range of scores between 5.3 and $18.6(M=13.8)$. No previous experimentation with the LSAT with adults has been conducted; therefore, no comparison can be made. However, it appears that despite the alteration in the administration of the two leveling-sharpening tasks, the general shape of the distribution of scores remains basically unchanged.

There are perhaps a variety of reasons why these predictions failed to materialize as expected. A major reason why these predictions failed to materialize could have been due to the design of the experiment. specifically, the overall $\mathbf{N}$ may have been too small and the 
median split technique used to divide subjects intto groups of levelers and sharpeners may not have been sufficiently powerful to create groups differing significantly along the dimensions specified for the cognitive control. A second reason could have been due to the alteration in the delivery of the leveling-sharpening tasks in this experiment from the conventional format. This could have served to greatly reduce the signal value of the stimulus material in the LSAT. As indicated in Figure 3 , there was a 15 second intertrial interval between each stimulus presentation. This alteration was necessary in order to acquire the heart rate data. However, it is counter to the conventional procedure which is to deliver each stimulus presentation consecutively for five seconds with no intertrial interval. Third, use of normal subjects and the manner in which the Edwards Personal Preference schedule was employed in this experiment as a measure of aggression may have been inappropriate. Finally, it is possible that the two leveling and sharpening tasks are not sufficiently related to truly measure differences in the leveling-sharpening process, or that some cognitive ability other than attention is reponsible for the differences between levelers and sharpeners. Each of these factors will be discussed in turn.

A possible explanation for these results centers around the use of the median split technique to divide subjects into groups of levelers and sharpeners. Because 
the obtained distribution of leveling-sharpening scores (table 4) was relatively narrow, dividing subjects on the basis of a median split could not create very different groups. Hence, the cognitive differences that were hypothesized may have been diluted. An alternative procedure might have been to construct groups of levelers and sharpeners who fell beyond the \pm lst deviation units. This would increase the differences between these groups and therefore would maximize the potential for elucidating the hypothesized cognitive differences between these groups. However, it would have been untenable to carry out such a procedure with the present data because the overall $\mathbf{N}$ would have been drastically reduced.

Another possible explanation for the failure to confirm the hypotheses in this experiment is that the alteration in the administration of the leveling-sharpening tasks is responsible for a reduction in the signal value of the tasks which resulted in a minimization of orienting behavior. According to the procedures detailed by Santostefano, the leveling-sharpening tasks are administered so that each card is presented consecutively for five seconds with no intertrial interval. Because the administration of these tasks had to be altered to accommodate the acquisition of the heart rate data, a task that typically takes five minutes to complete now required twenty minutes. More importantly a fifteen-second intertrial interval between stimulus presentations was incorporated into the 
administration of these tasks. The general increase of the time necessary to complete the task could have drastically altered the signal value of the task, hence reducing the significance of the stimuli material. Thus, in essence, the altered administration in both leveling-sharpening tasks made the task much less demanding and challenging.

Sokolov (1963) states that the orientation response is attributed to the effects of stimulus uncertainty. Thus, it is the discrepancy between the current stimulus input versus the internalized neuronal model that causes the orientation response. Sokolov further states that orienting behavior develops as the result of any change, removal, withdrawal or intensification of new stimulus material. Thus, for Sokolov, the role of stimulus novelty is the centerpoint for understanding why an orienting response occurs.

Given this characterization of the orientation response, it is logical to presume that the levelingsharpening tasks should have elicited orienting response behavior. A moderate level of attention and vigilance is required to perform the task. In addition, the manner on which the task changes from card to card would certainly insure that the stimulus material fulfills sokolov's requirements for stimulus mismatch. Further, the distribution of the leveling-sharpening ratios indicates that the alteration in task procedures did not necessarily result in drastically atypical leveling-sharpening ratios. Why then 
did the expected group differences in orienting responses fail to materialize?

The answer to this question may be found in research conducted by Bernstein (1969) and Bernstein and Taylor (1975). Bernstein contends that a mere informational mismatch between new, incoming stimuli and a pre-existing neuronal model of that information is not sufficient to produce measurably significant orienting behavior. Bernstein and Taylor (1975) contend that the orientation response is elicited by an interaction between two factors. These factors are 1) the informational value of the stimulus (e.g., novelty or mismatch) and 2) the potential usefulness of that information to the individual. Therefore, Sokolov's idea of stimulus mismatch is only the first step in understanding the origins of orienting behavior. Bernstein and Taylor state that while stimulus mismatch may result in a certain level of uncertainty for the individual, an orientation response will occur only when this uncertainty has some internal significance for the individual.

Reviewing some of Bernstein's research results on this issue will serve to make this point more meaningful. In an experiment designed specifically to examine how an individual's motivational state affects orienting behavior, Bernstein administered the following task. The stimulus consisted of a 1-second tachistoscopic presentation of a 6-5/8" square of white light. For the first ten trials the intensity was held constant (251x); on the eleventh trial 
the stimulus was changed $(51 x)$. Orienting behavior was measured throughout the experiment. After this procedure, post-experimental interviews were conducted to assess whether or not subjects were aware of the stimulus. On the basis of this interview subjects were assigned to one of three groups: those aware of the stimulus change, those who were indefinite about whether or not the stimulus change had occurred, and those who reported no stimulus change. statistically meaningful orienting behavior occurred only in this first group (those who could report the stimulus change). Interestingly, approximately half of the subjects who reported perceiving the stimulus change failed to exhibit an orientation response on trial 11 when the change occurred.

Bernstein interprets this data as indicating that the automatic-reflexive conceptionalization of orienting behavior is inadequate. Along with the perception of stimulus novelty or mismatch, a higher order cognitive process is also integral to the production of orienting behavior. This higher order cognitive process serves to evaluate the significance and usefulness of incoming information.

A third possible reason why this experiment failed to obtain the results as predicted may lie in the measure of aggression (EPPS) used in this experiment. In all of his previous research where differences in leveling and sharpening behavior were studied, Santostefano (1978, 1983, 
1984) used clinical populations and compared these subjects to a normal control group on a between group basis. In the experiments described above (Santostefano, 1983, 1984), where changes in the leveling-sharpening process were studied in groups of high and low aggressive children, not only was a clinical population selected, but subjects were selected who only scored particularly high or low on the measure that was employed to operationally define aggression. In this experiment, the EPPS, a measure that is supposed to measure an individual's predisposition towards aggression, was not statistically significant in relation to levelers' and sharpeners' HR scores in the manner predicted. The relative insensitivity of the EPPS could be because normal subjects were used in this experiment; therefore, the range of behavior the EPPS actually sampled could have been too narrow. Santostefano's $(1983,1984)$ aggressive subjects were residents in a psychiatric hospital. Certainly, college students, regardless of their scores on the EPPSAggressive scale, are not comparable to this type of clinical group.

A fourth possible explanation for these results centers on the hypothesized cognitive underpinning of the concept of leveling and sharpening. Attentional differences were hypothesized to be central to the leveling-sharpening phenomenon. However, in this study there were minimal changes in attention as measured by heart rate orientation responses. This suggests that attention as conceptualized 
above may not be as critical to the leveling-sharpening phenomenon as was hypothesized.

Why then did this experiment fail to show this psychophysiological, attentional distinction between levelers and sharpeners when Israel (1919) was able to show this distinction? Perhaps the discrepancy is due to the different methodologies used in the two studies. It must be remembered that Israel did not alter the administration of the leveling-sharpening tasks and that her assessment of the attentional component of the leveling-sharpening process was a completely separate procedure from her observations of leveling-sharpening behavior. In this experiment, psychophysiological measures of attention were taken while subjects were actually engaged in the leveling-sharpening tasks. It is possible that the alterations in procedure necessary in this study in order to measure heart rate and leveling and sharpening simultaneously minimized the attentional component of the leveling-sharpening task. Some other cognitive abilities such as visual scanning or the manner in which visual-spatial material is processed could, in fact, have become the major cognitive distinction between levelers and sharpeners. Hence, the diminished role of attention in the leveling-sharpening phenomenon in this study could have been an artifact of the changes in the methodology.

The results obtained in this research could also be due to the fact that Santostefano's concept of the 
cognitive-affective balance was unable to be adequately tested. According to this notion, progressions and regressions in leveling and sharpening are predictable given the context and one's psychological predisposition towards the situation in which leveling-sharpening occurs. In order to test this notion, one would need two tasks both measuring leveling-sharpening and differing only in the context in which the leveling-sharpening is operating. It was assumed on the basis of previous research (Santostefano, 1983, 1984) that the LSHT and LSAT met these criteria. However, the results of this study indicate that the two levelingsharpening tasks may not be as related to one another as was supposed. Support for this comes from the correlation between the two leveling-sharpening ratios which accounted for only a small portion of the variance. Further, the correlation between the first stop scores between the two leveling-sharpening tasks failed to reach significance at all. Thus, it is possible that there may be more than a contextual difference between these two tasks. For example, it is possible that the LSAT is perceptually more complex than the LSHT. This is supported by the fact that there was a significant difference in first stop scores between levelers and sharpeners only on the LSAT. If the perceptual qualities of the two tasks were equal, then it is reasonable to expect the levelers and sharpeners would also differ on the LSHT with respect to the first stop scores. 
paradigm used in this research might remediate the problems discussed above. First, as an alternative to constructing leveling-sharpening groups by using a median split technique, a larger $\mathrm{N}$ would allow one to construct groups from the tails of a distribution of leveling-sharpening ratios, thereby increasing the actual difference between these groups. Thus, if cognitive differences between groups exist, such a procedure would maximize such differences. Secondly, the leveling-sharpening tasks themselves could be altered. Specifically, the intertrial interval as well as the leveling-sharpening tasks themselves could be shortened. Instead of presenting 60 cards, as has conventionally been the case, there is no theoretical reason why the task could not be shortened to 30 or 40 cards. Both of these modifications might have made the tasks more challenging, thereby accentuating the hypothesized cognitive differences between these groups.

Thirdly, the use of a control group drawn from a clinical population might further elucidate the cognitive differences between levelers and sharpeners. Santostefano's (1983, 1984) findings of increased sharpening among high aggressive subjects has been replicated. Thus, the importance of using such a procedure is that subject groups are better defined and more distinct.

Lastly, using a measure of aggression other than EPPS, such as some behavioral rating scale or Santostefano's procedure of using responses from the Thematic Apperception 
Test card $18 \mathrm{MF}$ would probably create aggression groups of more ecological significance. 


\section{References}

Berlyne, D.E. (1960) Conflict arousal and curiosity. New York: McGraw-Hill.

Bernstein, A.S. (1969) To what does the orienting response respond? Psychophysiology, 6, 338-350.

Bernstein, A.S., Taylor, K.W., and Weinstein, E. (1975) The phasic electrodermal response as a differentiated complex reflecting stimulus significance. Psychophysiology, 12, 158-169.

Cannon, W.B. (1929) Bodily changes in pain, hunger, fear and rage. New York: Appleton.

Cousin, L.R. (1976) Individual differences in the orienting reflex and childrens' discrimination learning. Psychophysiology, 13, 479-489.

Darrow, C.W. (1929) Electrical and circulatory responses to brief sensory and ideational stimuli. Journal of Experimental Psychology, 12, 267-300.

Duffy, E. (1962) Activation_and behavior. New York: Wiley.

Gardner, R.W., Holzman, P.S. Klein, G.S., Linton, H.B. and Spence, D.P. (1959) Cognitive control: a study of individual consistencies. Psychological Issues, 1, No. 4.

Geer, H. (1969) Generalization of inhibition in the orienting response. Psychophysiology, 6, 197-201.

Graham, F.K. and Clifton, R. (1960) Heart-rate changes as a component of the orienting response. Psychological Bulletin, 63, 305-320.

Guthrie, G.D. (1967) Changes in cognitive functioning under stress: A study of plasticity of cognitive controls. Unpublished doctoral dissertation, Clark University, Worcester, MA.

Hare, R.D. (1972) Cardiovascular components of orienting and defensive responses. Psychophysiology, 2, 606-614.

Hartmann, H. (1958) Ego psychology and the problem of adaptation. New York: International Universities Press. 
Holzman, P. (1954) The relation of assimilation tendencies in visual, auditory, and kinesthetic time error to cognitive attitudes of leveling and sharpening. Journal of Personality, 22, 375-394.

Holzman, P. and Klein, G. (1954) Cognitive systems Principles of leveling and sharpening. Journal of Personality, 37, 105-122.

Holzman, P. and Gardner, R. (1960) Leveling, sharpening and memory organization. Journal of Abnormal Social Psychology, 61, 176-180.

Israel, N.R. (1966) Individual differences in GSR orienting response and cognitive control. Journal of Experimental Research in Personality, 1, 244-248.

Israel, N. (1969) Leveling and sharpening and anticipatory cardiac response. Psychosomatic Medicine, 31, 499-509.

Israel, N. (1970) Perception maintenance of attention: Leveling/sharpening differences on a random task. Perceptual and Motor Skills, 31, 571-581.

Klein, G. (1954) Need and regulation. In M.R. James (Ed.), Nebraska Symposium on Motivation. Lincoln: University of Nebraska Press, 1954.

Klein, G. and Schlessinger, H. (1949) Where is the perceiver in perceptual theory? Journal of Personality, 18, 32-47.

Lacey, J.I. (1967) Somatic response patterning and stress: Some revisions of activation theory. In M.A. Appley and R. Trumbull (Eds.) Psychological stress: Issues in research. New York: Appleton-Century-Crafts.

Lacey, B.C. and Lacey, J.I. (1978) Two-way communication between the heart and the brain: Significance of time within the cardiac cycle. American Psychologist, 33, 99-113.

Lacey, B.C. and Lacey, J.I. (1980) sensory-motor behavior behavior and cardiac activity. In I. Martin and P. Venables (Eds.), Techniques in Psychophysiology (pp. 170-179). New York: Wiley.

Lewis, M. and Wilson, C.D. (1970) The cardiac response to a perceptual cognitive task in the young child. Psychophysiology, $6,411-419$.

Maltzman, I. and Mandell, M.P. (1968) The orienting reflex as a predictor of learning and performance. Journal of Experimental Research in Personality, 3, 99-106. 
Obrist, P.A., Webb, R.A. and Sutter, J.R. (1969) Heart rate and somatic changes during aversive conditioning and a simple reaction time task. Psychophysiology, 5, 696-723.

Pavlov, I.P. (1927) Conditioned reflexes: An investigation of the physiological activity of the cerebral cortex. London and New York: Oxford University Press.

Raskin, D.C., Kotses, H. and Dever, J. (1969) Cephalic vasomotor and heart rate measures of orienting and defensive reflexes. Psychophysiology, 6, 149-159

Santostefano, S. (1978) A bio-developmental approach to clinical child psychology: cognitive controls and cognitive control therapy. New York: John Wiley.

Santostefano, S. (1983, June) Cognitive control and aggression in children: The concept of cognitive-affective balance. Paper presented to the 13th annual symposium of the Jean Piaget Society. Philadelphia, PA, June.

Shapiro, I.F. (1972) Cognitive controls and adaptation in children. Unpublished doctoral dissertation, Boston College.

Siddle, D.T. and Graham, T. (1980) Measurement and quantification and analysis of cardiac activity. In I. Martin and $P$. Venables (eds.) Techniques in Psychophysiology (pp. 139-178) New York: Wiley.

Sokolov, E. N. (1960a) Neuronal models and the orienting response. In Mary A. Brazier (Ed.) The central nervous system and behavior (pp. 545-579) New York: Josiah Macy Foundation.

Sokolov, E.N. (1960b) Higher nervous functions: The orientation reflex. Annual Review of Physiology, 25, 545-580.

Sokol ov E.N. (1963) Perception and the conditioned reflex. New York: Macmillan.

Spence, D.P., Lugo, M. and Youdin, R. (1974) Cardiac correlates of cognitive processing. Psychosomatic Medicine, 36, 420-437.

Tursky, B., Schwarts, G.E. and Creder, A. (1970) Differential patterns of heart rate and skin conductance during a digit transformation task. Journal of Experimental Psychology, 83, 451-457. 


\section{Appendix A}

\section{Leveling-Sharpening Instructions}

1.) Training Phase - Card 1 is presented and the examiner says, "Do you see this picture of a Christmas tree? I want you to look it over for a little while so that you can remember as much as you can about it. Then I will take it away and show you another picture of the same tree. When I take this picture away, I would like you to look at the next picture of the tree and tell me if the picture looks the same or whether anything has changed. Do you understand?"

Card 2 is then presented and the examiner says, "Now look over this picture of the tree. Is this picture the same as the one you just saw? Has it changed? Card 2 is presented for five seconds.

If a change is reported, the subject is asked to describe what has changed. Since the picture does not change, the subject is describing a change that has not occurred. If this occurs, Card $l$ is shown again, then it is placed face down and Card 2 is displayed again. The examiner says, "Now look at this picture again. Is this picture the same as the first or has it changed? If the subject indicates that the pictures are the same, the examiner says, "That's right." If a change is still reported, Cards 1 and 2 are held alongside each other and 
the subject is asked to look at the pictures simultaneously. The examiner says, "Look at this first one again and then look at the second one again. Do they look the same?" The subject is coached until it is established that the picture does not change.

Card 3 is presented. The examiner says, "Now look over this picture of the Christmas tree. Is the picture the same as the others or is it different?" The card is displayed for five seconds. If the subject correctly perceives the change Card 4 is presented. If the change is not perceived, the procedures described above are followed. This procedure is followed in displaying Cards 4, 5 and 6. After card 6 the examiner says, "Do you understand? I will be showing you one picture at a time for a little while. I want you to look at each picture as carefully as you can so you can remember what is in the picture so you can tell me if you see something change in the picture. If the picture looks the same, you do not have to say anything. If the picture does change, just say 'stop' and tell me what is different.

2.) Testing Phase - The examiner says, "I want you to look at the TV screen. I will be showing you pictures on the TV one at a time for just a little while. Please look at the picture as carefully as you can for as long as it is on the TV. After you see the first picture, if any of the other pictures look different or something has changed say 
'stop.' Then tell me what has changed. If the picture looks the same, you don't have to say anything at all. Remember, sometimes the pictures will look the same and sometimes they will look different. Okay? Ready?n

After this the examiner can make only two further comments: if a change has not been reported by Card 16 , the examiner will say, "Look at the picture carefully and say 'stop' if the picture looks different." If a change is reported again, the examiner says, "That's right. You already told me about that. You only need to tell me about the change once. Tell me when you notice something else changes or looks different." 


\section{Appendix B}

Raw Data for All Variables for All subjects

\begin{tabular}{|c|c|c|c|c|c|c|}
\hline Lev-Shp & Lev-Shp & Heart & Heart & Edwards & lst Stop & lst stop \\
\hline $\begin{array}{l}\text { Ratio } \\
\text { House }\end{array}$ & $\begin{array}{l}\text { Ratio } \\
\text { Aggress }\end{array}$ & $\begin{array}{l}\text { Rate } \\
\text { LSHT }\end{array}$ & $\begin{array}{l}\text { Ra te } \\
\text { LSAT }\end{array}$ & $\begin{array}{l}\text { Aggress } \\
\text { Scale }\end{array}$ & $\begin{array}{l}\text { Score } \\
\text { LSHT }\end{array}$ & $\begin{array}{c}\text { Score } \\
\text { LSAT }\end{array}$ \\
\hline 6.8 & 19.4 & -0.07 & 0.36 & 47 & 04 & 25 \\
\hline 9.1 & 21.8 & -1.09 & 0.58 & 14 & 10 & 28 \\
\hline 10.1 & 16.5 & -0.07 & -0.08 & 72 & 07 & 07 \\
\hline 10.4 & 14.3 & -0.22 & -1.02 & 66 & 11 & 13 \\
\hline 10.6 & 13.3 & 0.25 & 0.34 & 14 & 04 & 20 \\
\hline 10.8 & 11.3 & 0.39 & 0.71 & 47 & 06 & 13 \\
\hline 11.5 & 22.8 & -0.72 & -0.51 & 36 & 10 & 28 \\
\hline 11.3 & 16.8 & 0.50 & 0.75 & 51 & 08 & 08 \\
\hline 11.6 & 14.5 & -0.61 & 0.13 & 95 & 11 & 10 \\
\hline 11.6 & 12.2 & -1.17 & 0.27 & 09 & 10 & 08 \\
\hline 11.7 & 16.5 & $-0,17$ & -0.15 & 60 & 11 & 17 \\
\hline 11.7 & 15.4 & 0.36 & -2.18 & 51 & 10 & 10 \\
\hline 12.0 & 19.1 & -0.22 & 0.33 & 01 & 10 & 23 \\
\hline 12.2 & 12.3 & -0.11 & 0.35 & 01 & 11 & 09 \\
\hline 12.3 & 17.3 & -0.51 & 1.50 & 40 & 16 & 09 \\
\hline 12.5 & 21.7 & -0.46 & -0.15 & 57 & 10 & 29 \\
\hline 12.6 & 19.8 & -0.42 & 0.50 & 77 & 04 & 16 \\
\hline 12.7 & 22.0 & -1.65 & 0.83 & 14 & 05 & 34 \\
\hline 13.2 & 25.5 & -0.50 & 2.20 & 51 & 14 & 29 \\
\hline 13.2 & 22.9 & -0.89 & 0.34 & 57 & 15 & 29 \\
\hline 13.4 & 10.5 & -0.55 & -0.44 & 47 & 10 & 10 \\
\hline 13.4 & 09.8 & -0.71 & 0.92 & 32 & 10 & 18 \\
\hline 13.4 & 23.5 & 0.10 & -0.02 & 66 & 19 & 30 \\
\hline 13.6 & 22.1 & -0.39 & 0.03 & 36 & 10 & 28 \\
\hline 13.8 & 19.4 & 0.64 & 0.04 & 36 & 10 & 13 \\
\hline 13.8 & 20.3 & 0.21 & 0.54 & 44 & 10 & 28 \\
\hline 13.8 & 21.0 & 0.31 & 0.61 & 84 & 10 & 30 \\
\hline 13.8 & 21.7 & -1.12 & 1.34 & 09 & 10 & 28 \\
\hline 14.0 & 21.5 & 0.23 & 0.01 & 57 & 19 & 15 \\
\hline 14.1 & 24.3 & 0.42 & 0.42 & 72 & 10 & 28 \\
\hline 14.4 & 24.9 & -0.57 & -0.82 & 02 & 10 & 34 \\
\hline 14.4 & 22.0 & 0.21 & 0.89 & 01 & 10 & 29 \\
\hline 14.5 & 18.5 & -0.69 & 0.22 & 77 & 10 & 22 \\
\hline 14.6 & 21.1 & 0.29 & 0.03 & 77 & 10 & 28 \\
\hline 14.8 & 14.1 & 0.33 & -0.98 & 66 & 10 & 14 \\
\hline 15.6 & 23.5 & -0.26 & -0.12 & 65 & 10 & 30 \\
\hline 15.4 & 21.7 & -0.35 & 0.55 & 03 & 10 & 29 \\
\hline 15.1 & 22.8 & -0.58 & 0.15 & 09 & 14 & 20 \\
\hline 15.6 & 14.4 & -0.87 & 1.82 & 74 & 10 & 14 \\
\hline 16.1 & 23.7 & -0.47 & -0.50 & 79 & 10 & 29 \\
\hline 16.2 & 20.2 & -0.31 & -2.28 & 21 & 10 & 28 \\
\hline 17.0 & 15.4 & -1.00 & 1.78 & 79 & 25 & 14 \\
\hline 17.5 & 22.6 & -1.14 & -3.13 & 05 & 10 & 15 \\
\hline 17.6 & 23.1 & 0.80 & 0.18 & 36 & 11 & 28 \\
\hline
\end{tabular}


17.6

18.1

18.2

19.4
21.8

20.5

23.6

18.5 $\begin{array}{ll}-0.11 & 0.09\end{array}$

$-0.88$

$-0.27$

6.53
14

72

13

32
25

25

25

24
28

29

28

28 